\title{
The Implications of Differential Trends in Mortality for Social Security Policy
}

John Bound, Arline Geronimus, Javier Rodriguez, and Timothy Waidmann

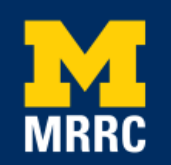

Project \#: UM14-11 


\title{
The Implications of Differential Trends in Mortality for Social Security Policy
}

\author{
John Bound \\ University of Michigan \\ Arline Geronimus \\ University of Michigan \\ Javier Rodriguez \\ University of Michigan \\ Timothy Waidmann \\ Urban Institute \\ October 2014 \\ Michigan Retirement Research Center \\ University of Michigan \\ P.O. Box 1248 \\ Ann Arbor, MI 48104 \\ www.mrrc.isr.umich.edu \\ (734) 615-0422
}

\section{Acknowledgements}

This work was supported by a grant from the Social Security Administration through the Michigan Retirement Research Center (Grant \# 2 RRC08098401-06-00). The findings and conclusions expressed are solely those of the author and do not represent the views of the Social Security Administration, any agency of the Federal government, or the Michigan Retirement Research Center. 


\title{
The Implications of Differential Trends in Mortality for Social Security Policy
}

\begin{abstract}
While increased life expectancy in the U.S. has been used as justification for raising the Social Security retirement ages, independent researchers have reported that life expectancy declined in recent decades for white women with less than a high school education. However, there has been a dramatic rise in educational attainment in the U.S. over the 20th century suggesting a more adversely selected population with low levels of education. Using data from the National Vital Statistics System and the U.S. Census from 1990-2010, we examine the robustness of earlier findings to several modifications in the assumptions and methodology employed. We categorize education in terms of relative rank in the overall distribution, rather than by credentials or years of education, and estimate trends in mortality for the bottom quartile. We also consider race and gender specific changes in the distribution of life expectancy. We found no evidence that survival probabilities declined for the bottom quartile of educational attainment. Nor did distributional analyses find any subgroup experienced absolute declines in survival probabilities. We conclude that recent dramatic and highly publicized estimates of worsening mortality rates among non-Hispanic whites who did not graduate from high school are highly sensitive to alternative approaches to asking the fundamental questions implied. However, it does appear that low SES groups are not sharing equally in improving mortality conditions, which raises concerns about the differential impacts of policies that would raise retirement ages uniformly in response to average increases in life expectancy.
\end{abstract}

\section{Citation}

Bound, John, Arline Geronimus, Javier Rodriguez, and Timothy Waidman. 2014. "The Implications of Differential Trends in Mortality for Social Security Policy.” University of Michigan Retirement Research Center (MRRC) Working Paper, WP 2014-314. Ann Arbor, MI. http://www.mrrc.isr.umich.edu/publications/papers/pdf/wp314.pdf

\section{Authors’ Acknowledgements}

The research reported herein was pursuant to a grant from the U.S. Social Security Administration (SSA), funded as part of the Retirement Research Consortium (RRC). The findings and conclusions expressed are solely those of the authors and do not represent the views of SSA, any agency of the federal government, the University of Michigan, or the Urban Institute. 
Increasing the Normal Retirement Age (NRA) is a frequently discussed reform to U.S. Social Security system. Given that life expectancy in the U.S. has increased substantially more than the retirement age since the establishment of the program, raising the normal retirement age further would seem a natural way to relieve financial pressure on the system. Indeed, simple models of optimal retirement policy have the property that individuals should work a constant fraction of their lives (Crawford and Lilien, 1981). However, one objection that has been raised to increasing the normal retirement age is that increases in life expectancy have not been equally shared across the U.S. population. There is a very long standing finding going back to work by Antonovsky (1967) and Kitagawa and Hauser (1973), which shows that, in the U.S., mortality rates tend to drop and life expectancy to rise with income, education, and other measures of socioeconomic status. There is also a recent literature that has argued that these differentials have been rising. Both Feldman, et al. (1989) and Preston and Elo (1995) find this pattern for educational differentials, while Waldron (2007), using Social Security Administrative data has found this pattern for earnings.

More dramatically, in a highly publicized paper (e.g., the paper was featured on the front page of the New York Times), Olshansky et al.(2012) use U.S. vital statistics and census data to estimate changes in life expectancy by race and education. Their dramatic finding was that between 1990 and 2008 the life expectancy among white men with less than a high school education fell by more than four years, while that for comparably educated white women fell by more than five years. While it is not hard to understand reasons why higher income, better educated individuals might disproportionately gain from medical advances (Goldman and Lakdawalla 2005), significant drops in life expectancy are surprising and largely unprecedented in developed countries outside of periods of large-scale wars. A number of authors have argued that the increased prevalence of such chronic diseases as diabetes foreshadows a drop in life expectancy in the U.S. and other developed countries, and the rise in the prevalence of diabetes has been concentrated amongst the less well educated, but until Olshansky and colleagues published their paper, few imagined that dramatic declines had already occurred in subsets of the U.S. population. 
We believe that there are a number of reasons to question the validity of Olshansky et al.'s conclusions. As the authors note, life table estimates for the elderly tend to be unreliable, and they use procedures that are both reasonable and standard to estimate age specific mortality rates for the 85+ population. However, if their conclusion is sensitive to those methods, we should question the robustness of their conclusion and exercise caution in making policy based on it. More fundamentally, we know that educational attainment rose dramatically in the U.S. over the 20th century, with high school graduation rates rising from less than $10 \%$ in 1900 to close to $80 \%$ by 1970 . As a result, between 1990 and 2008 the population of high school dropouts at high risk of dying would have become substantially more selective, making comparisons of life expectancy over time within this group problematic.

\section{Data and Methods}

In this paper we examine the robustness of the Olshansky group’s conclusions to several modifications in their assumptions and methodology. Following Olshansky et al., we used data from the Multiple Cause of Death public use files, which contain individual level information on decedents in the United States, including cause(s) of death, age, sex, race, ethnicity, educational attainment, and marital status. To estimate the population at risk of death using the same covariates, we use data for U.S. residents collected by the U.S. Census Bureau (Ruggles et al., 2010). From 1940 to 2000, information on age, race, and educational attainment comes from the long-form of the decennial census. In 2010, after the decennial long-form was discontinued, this information is obtained from a three-year (2009-2011) pooled sample of the American Community Survey which samples approximately one percent of the U.S. population every year. We examine three potential explanations for the findings of Olshansky et al.

1. Focus on the Population Aged 25-84. Our first analysis is on the sensitivity of Olshansky's finding to the standard methods for dealing with poor data quality among the very old. In particular, if age misreporting occurs more frequently in populations with low levels of education than in those with higher levels, mortality comparisons that include these ages will be compromised. Olshansky et al. employ complicated, yet fairly standard, methods to correct for 
this problem at ages 85-110 (Coale and Kisker, 1990). However, if total remaining life expectancy for high school drop outs at age 25 has truly fallen, it is most likely because mortality rates for this group have increased between ages 25 and 84, rather than at older ages. First, life expectancy is disproportionality affected by mortality rates at younger ages, and second, socioeconomic differentials in mortality rates tend to narrow with age. Thus, focusing our attention on mortality between 25 and 84 can be viewed as a check on the robustness of the Olshansky group’s findings using the entire age range.

Using standard methods, we calculated race, sex, education, and age-specific mortality rates by five year age groups for non-Hispanic whites (hereafter, white) and non-Hispanic Blacks (hereafter, black) in 1990, 2000, and 2010. We combined these rates to produce two types of aggregate measures. First, using the sex-specific age distributions of the combined white and black populations, we constructed age-and-race-standardized mortality rates by sex and education. Consistent with Olashansky et al., we categorized educational attainment into four broad groups, those without a high school diploma, those with a high school diploma, but not college, those with some college, and those with a four-year college degree. Comparing these standardized rates over time reflects only changes in age-and-race-specific mortality rates and not the distributions of age and race. Second, using the age-race-sex-education specific death rates, we constructed period life table survival rates for ages 30 to 85 conditional on survival to age 25 (Chiang, 1984).

While education has been imputed in census data, the same is not true in vital statistics data. Depending on the year, between two and 18 percent of death certificates do not report a level of education, and must be imputed. There are two sources of missing education data in these records. First, in two of the years examined, several states (seven in 1990 and three in 2000) reported no education information on the death certificate. Second, in every other state, a small share of death certificates had missing information. In the states where only some data were missing, we used the distribution of educational attainment in non-missing cases, by age, sex, and race, to impute education to the missing cases, assuming that education was missing randomly. To deal with missing states, we calculated mortality rates using the population data 
only from states that reported education on the death certificate. To check the sensitivity of our results to this procedure, we calculated age-sex-race specific mortality rates for 2000 in two ways: first using the 43 states and the District of Columbia that had data available in 1990, and then using the 47 states and D.C. that had data available in 2000. Applying these two sets of mortality rates to the national population in 2000 resulted in minimal differences in the standardized mortality rates and survival probabilities.

2. Categorizing Education by Rank. As shown in Figure 1, according to census data, the fraction of persons reaching age 25 who had completed the $12^{\text {th }}$ grade changed dramatically over the $20^{\text {th }}$ century. ${ }^{1}$ This raises the possibility that the apparent drop in the life expectancy of high school dropouts is a result of an increasingly narrow and selective nature of dropouts. To assess this possibility, we instead categorize education in terms of relative ranks in the overall distribution, rather than by credentials or years of education. Using census data, we estimated the $25^{\text {th }}$ percentile of educational attainment for each birth cohort by race and sex, which is shown in Figure 2. Using these cuts, we then use education as reported on the death certificate to calculate trends in mortality rates between 1990 and 2010 for those in the bottom quartile of the education distribution.

3. Distribution of Life Expectancies. Finally, one implication of Olshansky et al.'s work is that some parts of the population have experienced increases in life expectancy, while others have actually seen life expectancy drop. An alternative way to look at this question is to ask whether the variation in years lived has increased, with an increasing fraction of the population dying prematurely at the same time as an increasing share lives into old age. Asking the question in this way avoids a number of thorny questions about how to define a population (relative vs. absolute attainment) and also avoids issue of the comparability of education coding and imputation between census and vital statistics data. ${ }^{2}$

\footnotetext{
${ }^{1}$ For each cohort, we used the census data file from the first appearance of the cohort after they turned age 25. Thus, for cohorts born 1905-1915, we used the 1940 decennial census; for cohorts born 1916-1925, we used the 1950 decennial, etc.

${ }^{2}$ In particular, recent research using matched CPS and death certificate data (Rostron \& National Center for Health Statistics (U.S.), 2010) has found evidence consistent with misreporting of education on death certificates, especially in reporting high school graduation. These errors vary by race and ethnicity, and can have substantial impact on life expectancy estimates.
} 
We address the question of diverging mortality in several ways. First, for each gender and race specific group, we first estimate the interquartile range (IQR) of life expectancy for persons who survive to age 25, a value relatively easy to calculate, but shown to be highly correlated with many measures of variability (Wilmoth and Horiuchi 1999). If a segment of the population is falling behind in absolute terms while the rest is improving, we should expect to see a widening of the IQR over time. Second, we use standard life table methods to estimate the probability an individual alive at the age of 25 will reach the age of 35, 45, 55, 65, 75, and 85 in 1990, 2000, and 2010. If some portions of the population have experienced shortening life expectancies, while others have experienced increases in life expectancy, what we should see are decreases in the chances that an individual reaches the ages of 35, 45, 55, or 65 while at the same time seeing increases in the probability that someone will reach the age of 75 or 85 .

\section{Results}

Mortality by educational attainment between 25 and 85. To see whether the Olshansky et al. finding of increasing mortality among low education groups is driven by age misreporting and other complications of measuring old-age mortality, we limited the analysis to mortality between the ages of 25 and 84, when premature mortality is most likely to have an effect on the low SES group. Figure 3 plots survival curves from age 25 to 84 for non-Hispanic black and non-Hispanic white women and men in 1990 and 2010, derived from period life tables. Consistent with Olshansky et al., who compared 1990 and 2008, we find that survival probabilities for nonHispanic whites with less than a high school education declined between 1990 and 2010. If the age-specific rates of mortality observed in 1990 held throughout their lives, a 25-year old white woman with less than a high school education had a 40.9 percent chance of surviving to age 85 . Under the rates observed in 2010, the same woman had only a 31.4 percent chance of surviving to age 85. The same probability for white men with less than a high school education decreased from 17.6 percent to 16.7 percent between 1990 and 2010. Also consistent with past research, 
we found that Non-Hispanic black women and men did not show the same patterns. Between 1990 and 2010, the probability of survival from age 25 to age 85 increased from 31.3 percent to 34.4 percent for black women and from 10.5 percent to 17.0 percent for black men with less than a high school education. It should also be noted that while black women and men gained relative to whites between 1990 and 2010, black women and men still had a substantial mortality disadvantage in 2010 within each level of education.

Mortality rates by quartile rank in educational attainment. The dramatic increase in educational attainment during the $20^{\text {th }}$ century meant that the population with less than a high school education has grown increasingly select. To check whether this selectivity is behind the declines in survival probabilities among whites, we constructed life tables for white women and men in the lowest quartile of educational attainment for persons born in the same year of the same sex and race. The data in Figure 2 show the thresholds that define the bottom quartile as derived from census data on educational attainment that was collected for each birth cohort when they were between the ages of 25 and 35. In Figure 4, we plot the survival curves for the lowest quartile and the combined top three quartiles. We find that between 1990 and 2010, in contrast to the findings above, white women in the bottom quartile had no appreciable change in survival, while women in the top three quartiles saw an increase in survival probability to every age. Even more dramatically, among white men, both the lowest quartile and the top three quartiles saw increased survival probabilities between 1990 and 2010, though the gains for those in the bottom quartile were not as great as those for the top three quartiles. Thus, when one categorizes education by rank, one does not see any evidence that survival probabilities have declined for the bottom quartile of educational attainment. However, consistent with other findings (e.g., Waldron, 2007) we do see clear evidence for increasing dispersion of survival probabilities between those in the bottom and top of the educational distribution.

Distribution of Life Expectancies. Finally, because of the problems discussed above in aligning vital statistics and population data on education, an alternative way of examining the finding of diverging mortality is to look at changes in the distribution of the age at death. If some portion of the population is experiencing absolute declines in survival probabilities, we would 
expect not only a widening of the distribution of ages at death, but also an absolute decline at some common percentile of the distribution. This is not what we observe, however. First, in Figure 5 we show the distribution of life table deaths by age $\left(d_{x}\right)$, based on published life tables. Black and white men show a consistent improvement (rightward shift) and compression of age at death from 1990 to 2010. Black and white women appear to have some compression between 1990 and 2000, but little shift. Between 2000 and 2010, however all groups show both improvement and compression. In Figure 6, looking just at survival probabilities after age 25, these findings are largely confirmed. White women show no improvement between 1990 and 2000, while black women show very slight improvement. Both groups of men show consistent improvements. If there had been decreased survival for some portion of the population and increased survival for others, we would expect to see an upward shift in older ranges of these curves over time and a downward shift at younger ages, producing a crossing of the survival curves from two successive periods.

To see this another way, in Figure 7 we show the $10^{\text {th }}, 25^{\text {th }}$, and $75^{\text {th }}$ percentiles of the distributions of expected age at death for non-Hispanic black and white women and men, for persons who have survived to age 25. As expected with demonstrated improvements in life expectancy overall, the $75^{\text {th }}$ percentile of the age-at-death distribution increased for each group between 1990 and 2010. On the other hand, each group other than white women also shows an increase in the $10^{\text {th }}$ percentile of age at death. This value improved most dramatically for black men, increasing from 44 to 52; it increased from 55 to 57 for black women. The $10^{\text {th }}$ percentile of age at death for white men showed a slight increase from 56 to 57, while for white women, the $10^{\text {th }}$ percentile held constant at 63 . For every group the $25^{\text {th }}$ percentiles of these distributions also increased. Finally, looking at changes in the interquartile range as a summary measure of dispersion shows that all groups but white men have had a small decrease in the dispersion of life expectancies. The IQR for white men increased slightly from 17 years in 1990 to 18 years in 2010. As is the case in overall survival, for both men and women, the IQR for blacks is higher than for whites. One interesting pattern to note is that in the tabulations by race and sex, we see less consistent evidence of increased dispersion in expected age of death than when we compare 
the better with the less well educated. At least for whites, this suggests that while dispersion $\underline{\text { across }}$ SES groups appears to be widening, the reverse may be true within groups. There is nothing necessarily contradictory in these findings. It is entirely possible that while advantaged groups would have disproportionately shared in the growth in life expectancy, other factors are leading to a compression of mortality.

Another relevant way to look at this data is to ask how the fraction of those alive at age 25 would reach the ages of 65, 75, or 85 . Between 1990 and 2010, the fraction of white men who would die before reaching the Social Security Normal Retirement Age (age 65) dropped a bit from 0.21 to 0.18 . For women the drop was even smaller, from 0.12 to 0.11 . In contrast, the change in the fraction who would reach 85 rose from 0.25 to 0.35 for white men and from 0.45 to 0.49 for white women. For blacks, we see a different pattern. While increases in survival to age 85 were similar in magnitude to those experienced by whites, blacks had much larger increases in survival to 65. In 1990, the fraction of adult black men alive at age 25 who would die before reaching 65 was 0.38! By 2010, while still high relative to whites, this fraction had declined to 0.28. For black women, in 19900.22 would die before 65. By 2010 this number had dropped to 0.18 .

\section{Discussion}

Our findings on changing mortality conditions between 1990 and 2010 can be viewed as a refinement of past work on socioeconomic disparities in the U.S. Consistent with recent findings on disparity in economic outcomes (U.S. Census Bureau, 2013), mortality also appears to be trending toward more inequality, at least when the contrasts are between higher and lower SES groups. However, when we categorize individuals by rank in the distribution of educational attainment, we do not find evidence consistent with absolute increases in mortality at the lowest levels of SES. While we are able to replicate recent dramatic estimates of worsening mortality rates among non-Hispanic whites who did not graduate from high school, we find that a possible explanation for these trends is that this group is becoming less and less common over time, and thus represents a more disadvantaged group now than it did even 20 years ago. When we look at 
the low end of the educational distribution in a different way, attempting to hold relative economic position constant, we do not find that those at the low end of the distribution lost ground in absolute terms. They have, however, lost ground in relative terms.

Taken together, these findings suggest that care should be taken in interpreting evidence of falling life expectancy among low SES groups. However, it does appear that low SES groups are not sharing equally in improving mortality conditions, which raises concerns about the differential impacts of policies that would raise retirement ages uniformly in response to average increases in life expectancy. 


\section{References}

Chiang, Chin Long. 1984. The Life Table and Its Applications. Malabar, Fla: R.E. Krieger Pub.

Coale, Ansley J, and Ellen E Kisker. 1990. "Defects in Data on Old-Age Mortality in the United States: New Procedures for Calculating Mortality Schedules and Life Tables at the Highest Ages.”

Crawford, Vincent P, and David M Lilien. 1981. "Social Security and the Retirement Decision.” The Quarterly Journal of Economics, 505-29.

Feldman, Jacob J, Diane M Makuc, Joel C Kleinman, and Joan Cornoni-Huntley. 1989. "National Trends in Educational Differentials in Mortality." American Journal of Epidemiology 129 (5): 919-33.

Goldman, Dana P, and Darius N Lakdawalla. 2005. “A Theory of Health Disparities and Medical Technology.” Contributions in Economic Analysis \& Policy 4 (1).

Kitagawa, Evelyn M, and Philip M Hauser. 1973. Differential Mortality in the United States: A Study in Socioeconomic Epidemiology. Vol. 35. Harvard University Press Cambridge, MA.

NVSS - Mortality Tables - Life Expectancy. 2014. Accessed July 24. http://www.cdc.gov/nchs/nvss/mortality/lewk3.htm.

NVSS - Public Use Data File Documentation. 2014. Accessed July 19. http://www.cdc.gov/nchs/nvss/mortality_public_use_data.htm.

Olshansky, S Jay, Toni Antonucci, Lisa Berkman, Robert H Binstock, Axel Boersch-Supan, John T Cacioppo, Bruce A Carnes, Laura L Carstensen, Linda P Fried, Dana P Goldman, James Jackson, Martin Kohli, John Rother, Yuhui Zheng, and John Rowe. 2012. "Differences in Life Expectancy due to Race and Educational Differences Are Widening, and Many May Not Catch up.” Health Affairs 31 (8): 1803-13.

Preston, Samuel H, and Irma T Elo. 1995. “Are Educational Differentials in Adult Mortality Increasing in the United States?” Journal of Aging and Health 7 (4): 476-96.

Rostron, B. L., \& National Center for Health Statistics (U.S.). (2010). Education reporting and classification on death certificates in the United States. Hyattsville, Md. : Washington, DC: U.S. Dept. of Health and Human Services, Centers for Disease Control and Prevention, National Center for Health Statistics ; For sale by the U.S. G.P.O., Supt. of Docs.

Ruggles, Steven, J. Trent Alexander, Katie Genadek, Ronald Goeken, Matthew B. Schroeder, and Matthew Sobek. 2010. "Integrated Public Use Microdata Series: Version 5.0 [Machine-Readable Database]”. University of Minnesota. usa.ipums.org. 
U.S. Census Bureau. 2013. Table A3: Selected Measures of Household Income Dispersion: 1967 to 2010. https://www.census.gov/hhes/www/income/data/historical/inequality/IE-1.pdf.

Waldron, Hilary. 2007. “Trends in Mortality Differentials and Life Expectancy for Male Social Security-Covered Workers, by Socioeconomic Status.” Soc. Sec. Bull. 67: 1.

Wilmoth, John R, and Shiro Horiuchi. 1999. "Rectangularization Revisited: Variability of Age at Death within Human Populations*.” Demography 36 (4): 475-95. 
Figure 1: Percent completing 12th grade, by race, sex, and birth year

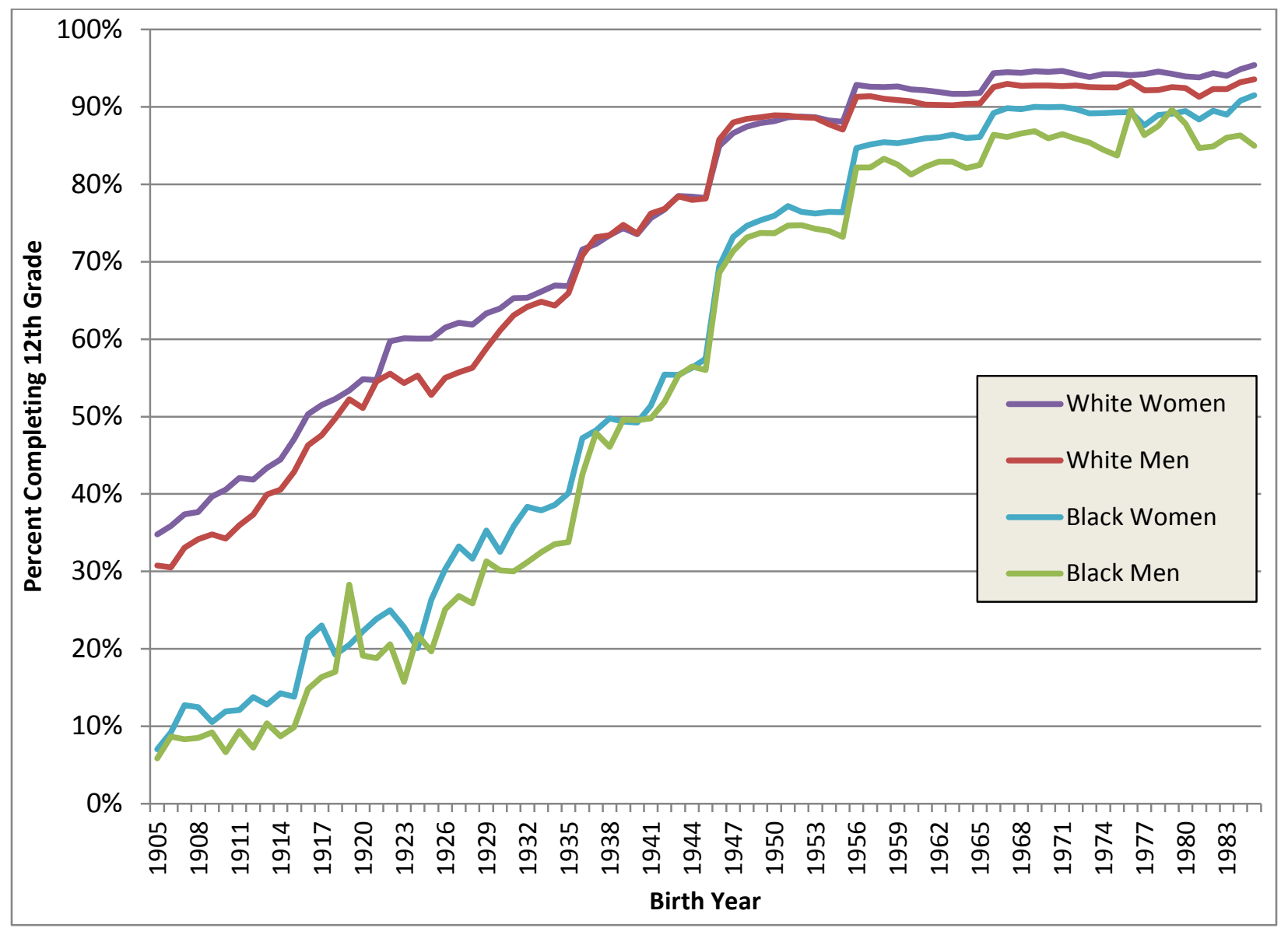

Source: Authors’ tabulations based on U.S. Census data (Ruggles et al. 2010). 
Figure 2:25th Percentile of Educational Attainment at age 25, by race, sex and birth year

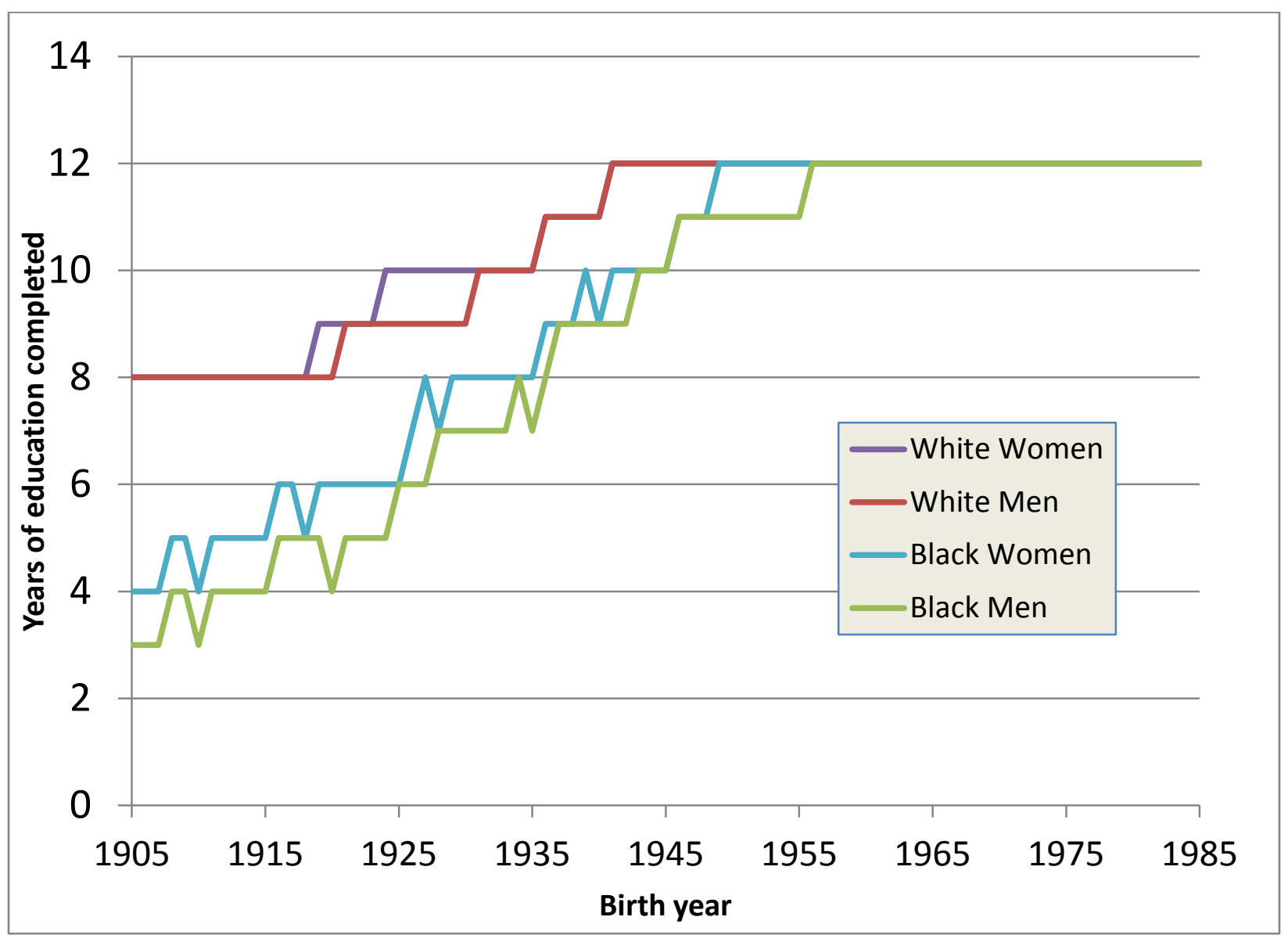

Source: Authors’ tabulations based on U.S. Census data (Ruggles et al. 2010). 
Figure 3: Survival Curves, by race, sex, and year for persons with less than high school education and college graduates, 1990 and 2010
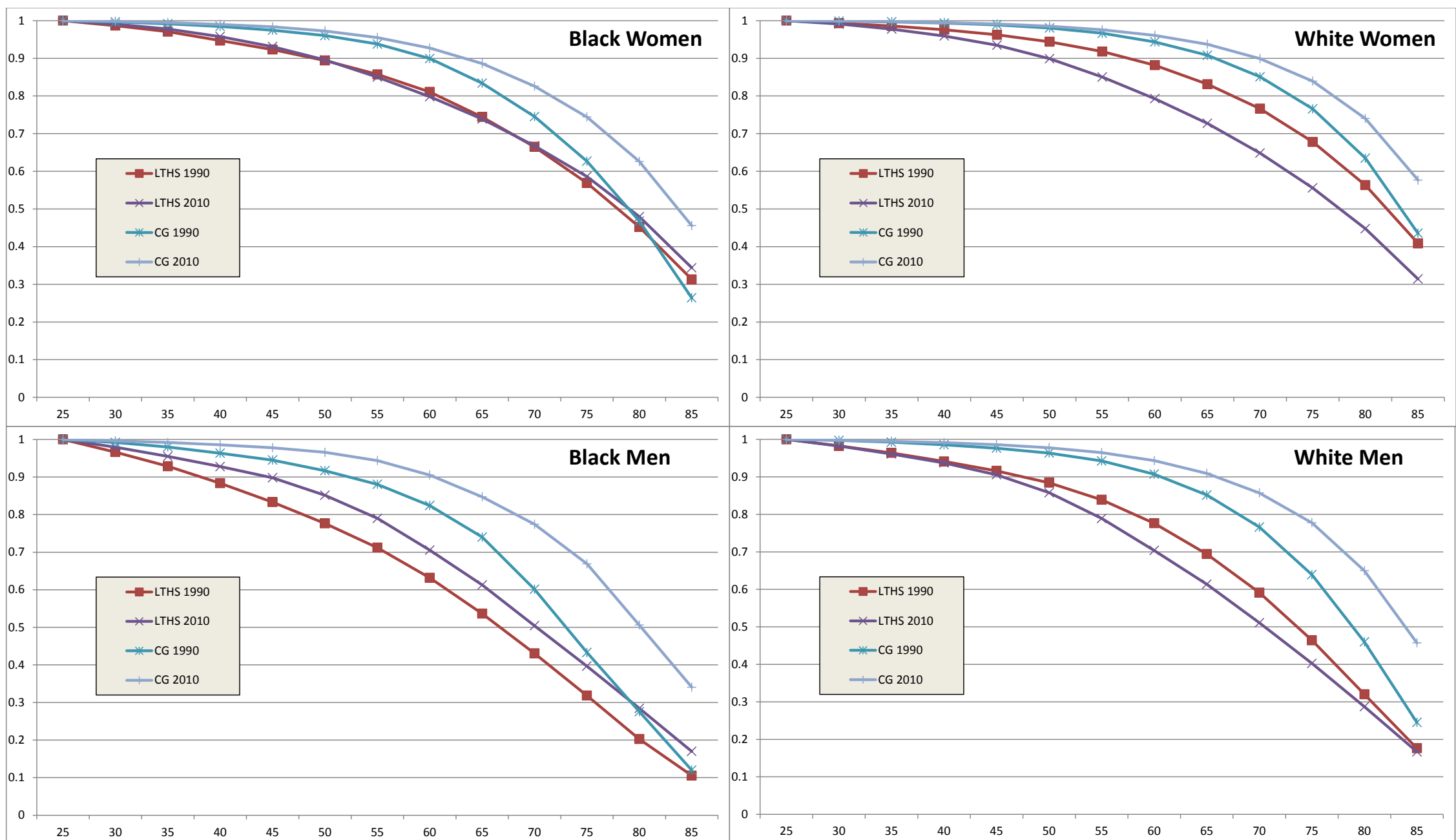

Source: Authors' tabulations based on National Vital Statistics System multiple cause of death data ("NVSS - Public Use Data File Documentation” 2014) and U.S. Census data (Ruggles et al. 2010). See Appendix Table 1 for values. 
Figure 4: Survival Curves by educational rank, white men and women, 1990 and 2010

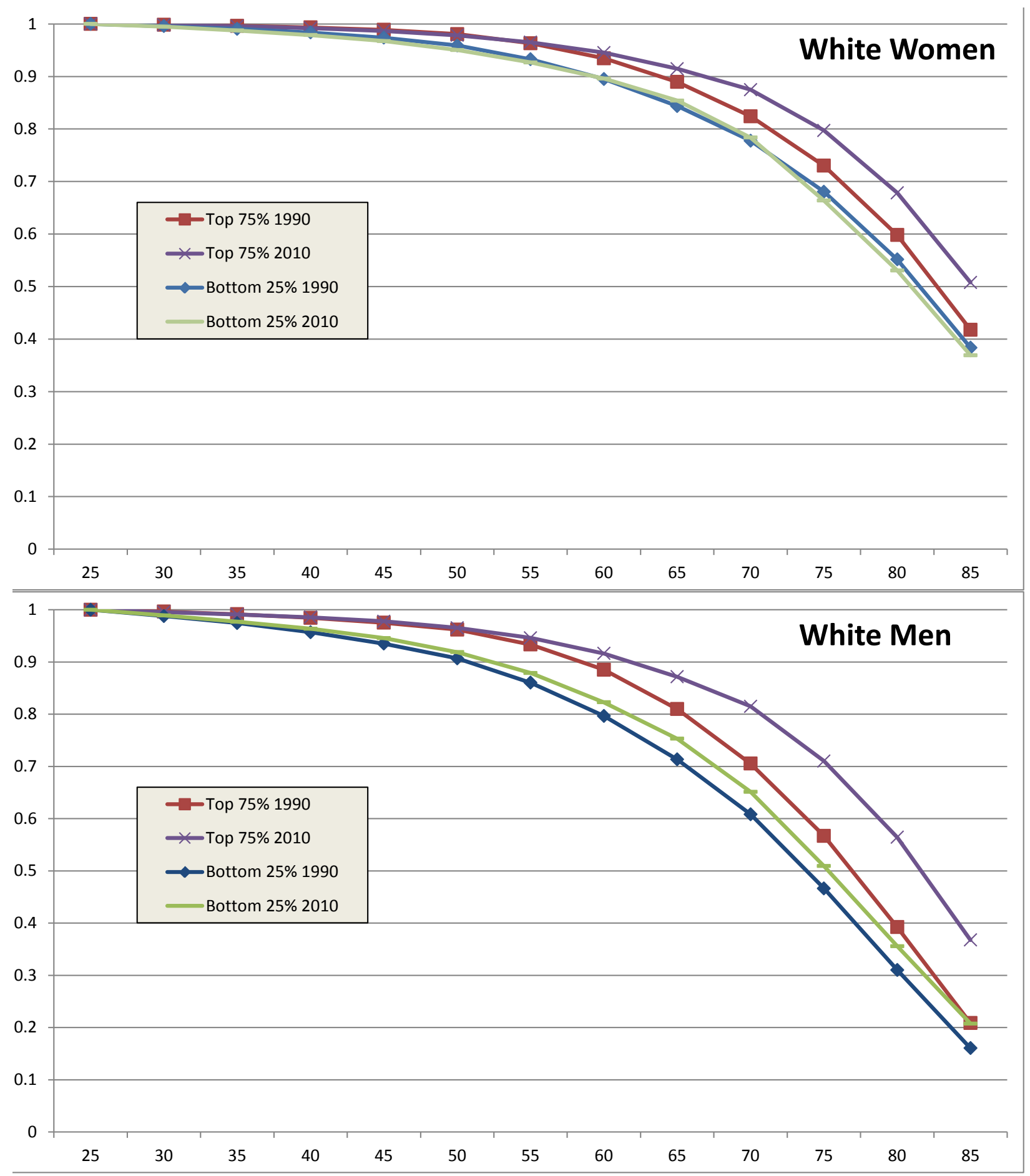

Source: Authors' tabulations based on National Vital Statistics System multiple cause of death data ("NVSS - Public Use Data File Documentation” 2014) and U.S. Census data (Ruggles et al. 2010). See Appendix Table 2 for values. 
Figure 5:Density of life table deaths (dx), by sex and race
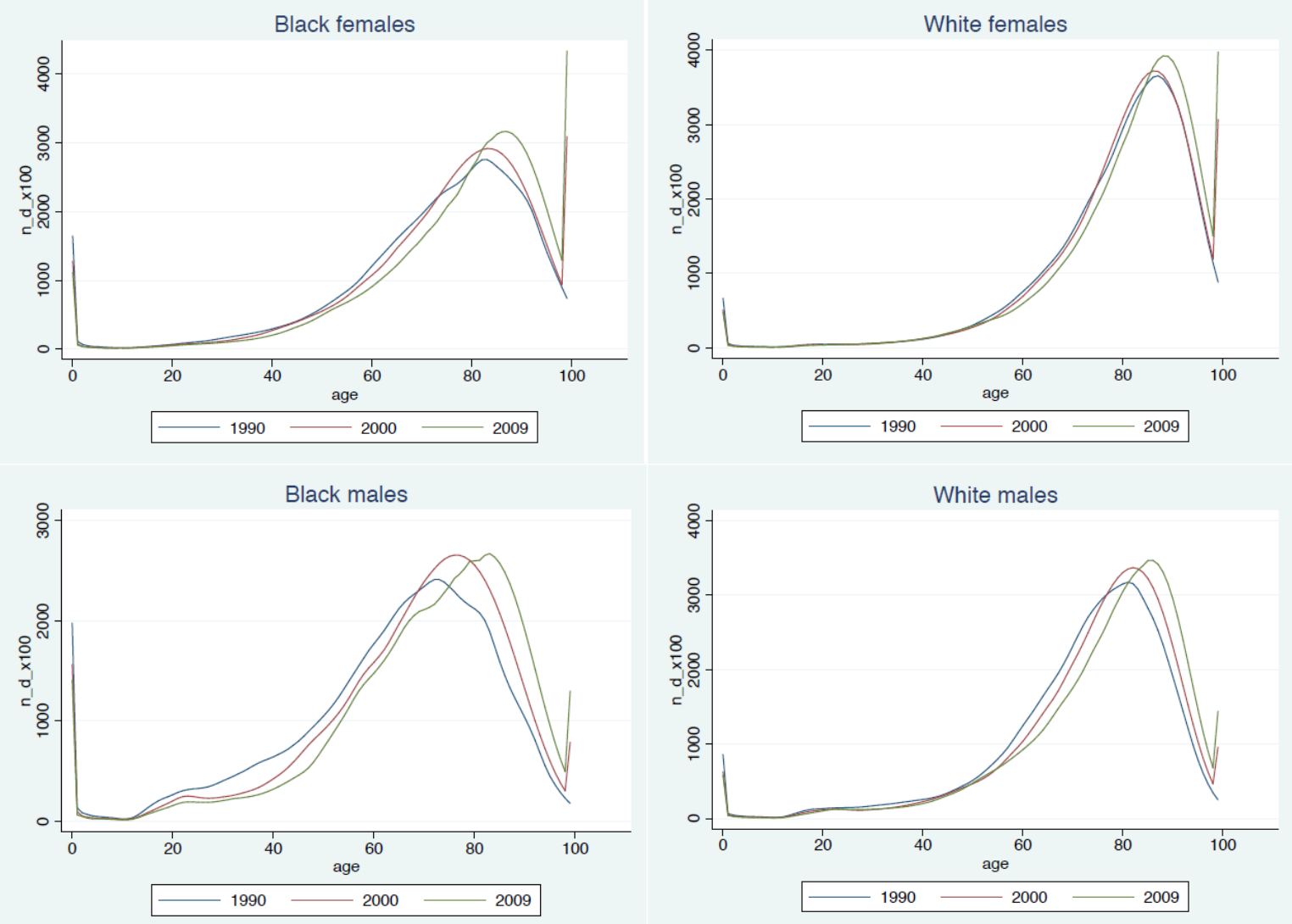

Source: Authors’ tabulations based on published life tables.(“NVSS - Mortality Tables - Life Expectancy” 2014) 
Figure 6: Survival Probabilities by sex and race in 1990, 2000, and 2010

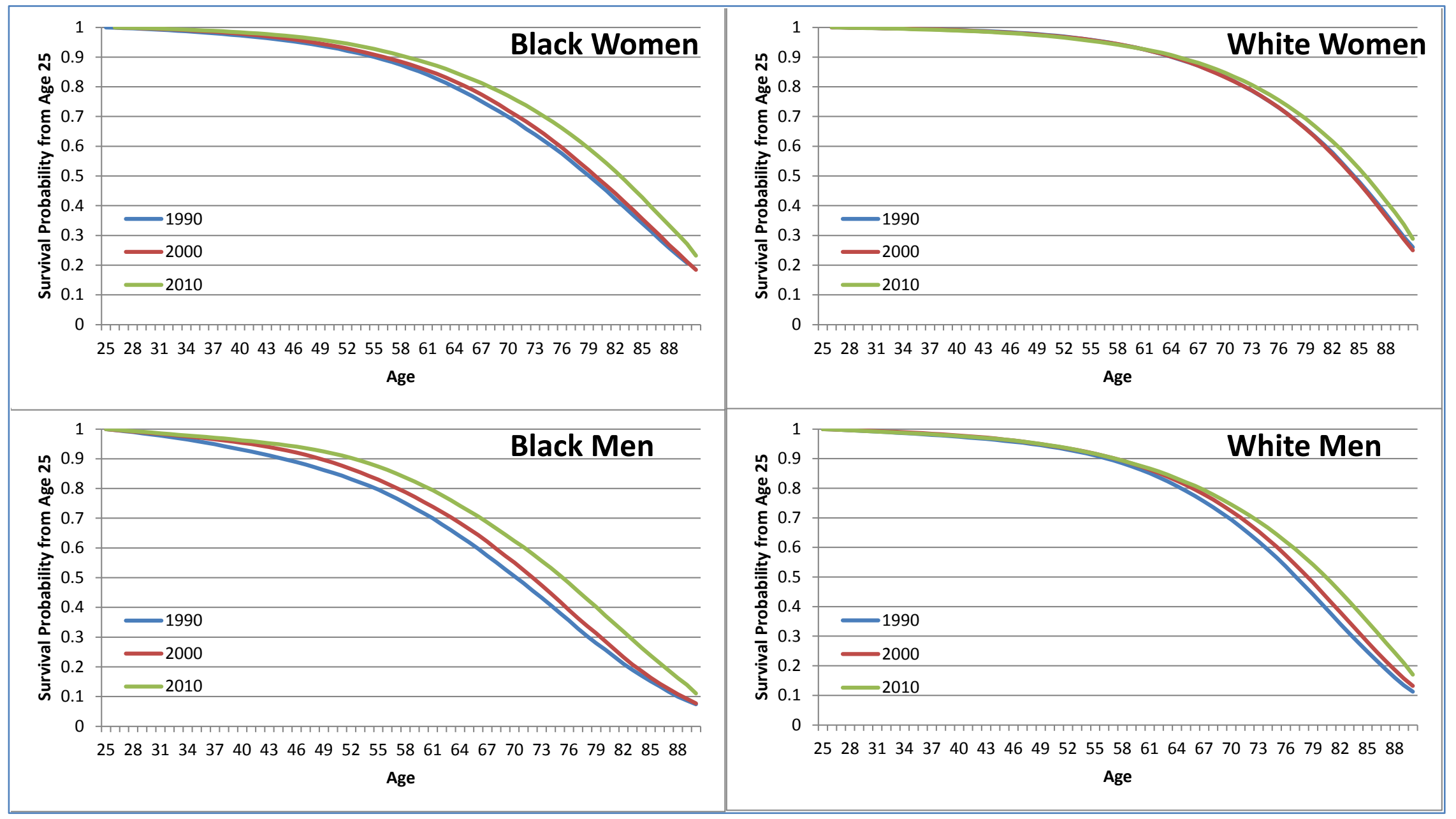

Source: Authors' tabulations based on National Vital Statistics System multiple cause of death data (“NVSS - Public Use Data File Documentation” 2014) and U.S. Census data (Ruggles et al. 2010). 
Figure 7: Distribution of Expected Age at Death (age 25+), by sex and race, 1990-2010

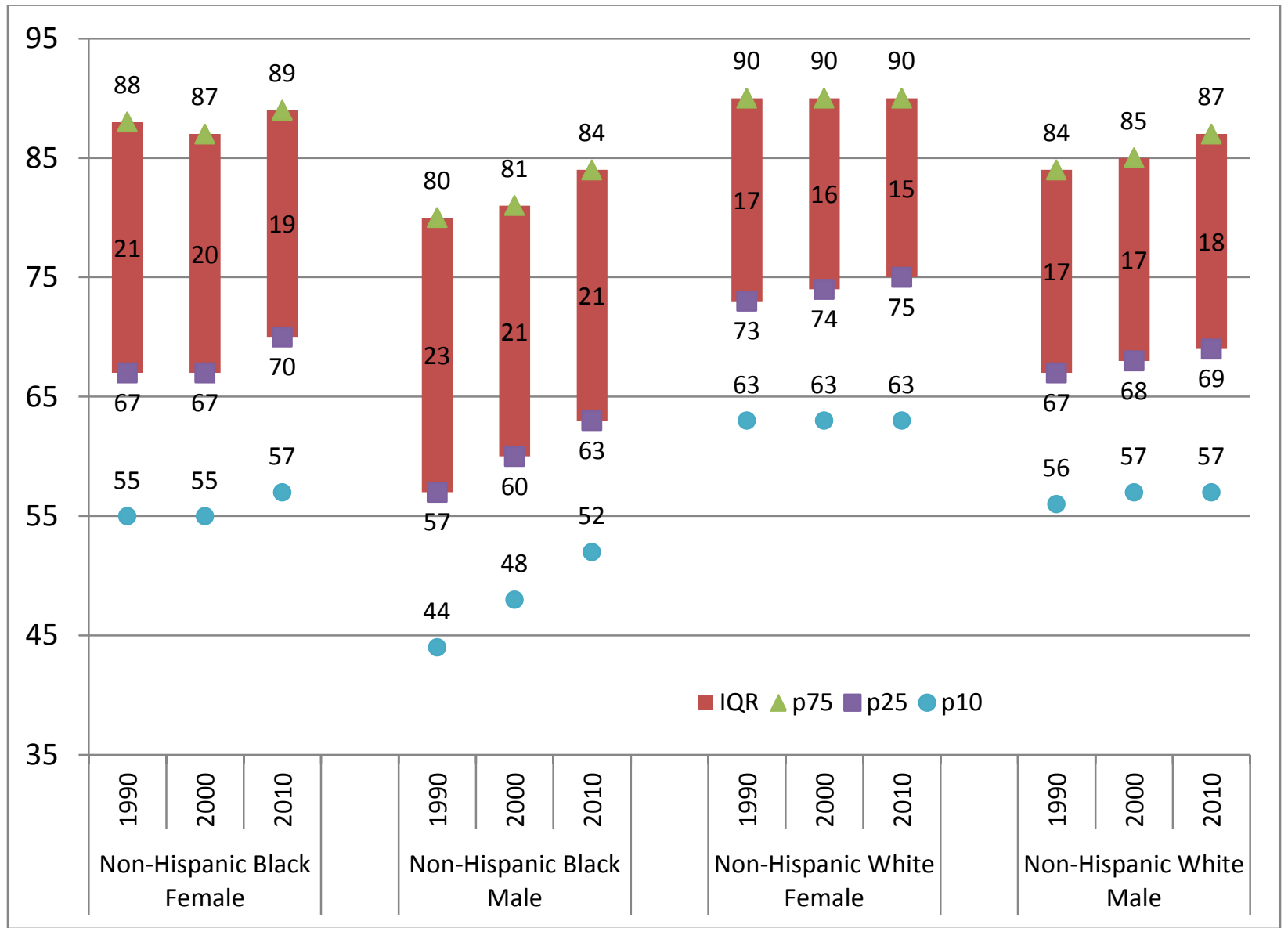

Source: Authors' tabulations based on National Vital Statistics System multiple cause of death data ("NVSS - Public Use Data File Documentation,” n.d.). 
Appendix Table 1: Life Table Survival Probabilities, conditional on survival to age 25, by level of education

\begin{tabular}{|c|c|c|c|c|c|c|c|c|c|c|c|c|}
\hline \multirow[b]{3}{*}{ Age } & \multicolumn{12}{|c|}{ Non-Hispanic Black Female } \\
\hline & \multicolumn{3}{|c|}{ Less than High School } & \multicolumn{3}{|c|}{ High School Graduate } & \multicolumn{3}{|c|}{ Some College } & \multicolumn{3}{|c|}{ College Graduate } \\
\hline & 1990 & 2000 & 2010 & 1990 & 2000 & 2010 & 1990 & 2000 & 2010 & 1990 & 2000 & 2010 \\
\hline 25 & 1.00 & 1.00 & 1.00 & 1.00 & 1.00 & 1.00 & 1.00 & 1.00 & 1.00 & 1.00 & 1.00 & 1.00 \\
\hline 30 & 0.987 & 0.988 & 0.991 & 0.992 & 0.993 & 0.993 & 0.996 & 0.997 & 0.997 & 0.996 & 0.997 & 0.998 \\
\hline 35 & 0.971 & 0.971 & 0.978 & 0.981 & 0.982 & 0.984 & 0.992 & 0.992 & 0.993 & 0.991 & 0.994 & 0.995 \\
\hline 40 & 0.947 & 0.950 & 0.958 & 0.965 & 0.968 & 0.972 & 0.985 & 0.986 & 0.988 & 0.985 & 0.988 & 0.990 \\
\hline 45 & 0.923 & 0.919 & 0.931 & 0.944 & 0.946 & 0.956 & 0.975 & 0.976 & 0.980 & 0.975 & 0.977 & 0.984 \\
\hline 50 & 0.894 & 0.882 & 0.896 & 0.915 & 0.914 & 0.930 & 0.960 & 0.960 & 0.966 & 0.960 & 0.961 & 0.973 \\
\hline 55 & 0.857 & 0.838 & 0.850 & 0.873 & 0.871 & 0.891 & 0.936 & 0.937 & 0.944 & 0.938 & 0.936 & 0.955 \\
\hline 60 & 0.811 & 0.790 & 0.798 & 0.810 & 0.814 & 0.839 & 0.897 & 0.903 & 0.913 & 0.899 & 0.901 & 0.927 \\
\hline 65 & 0.744 & 0.728 & 0.739 & 0.723 & 0.736 & 0.774 & 0.840 & 0.858 & 0.868 & 0.834 & 0.847 & 0.886 \\
\hline 70 & 0.665 & 0.648 & 0.668 & 0.607 & 0.632 & 0.692 & 0.761 & 0.784 & 0.808 & 0.745 & 0.770 & 0.826 \\
\hline 75 & 0.569 & 0.552 & 0.586 & 0.473 & 0.506 & 0.586 & 0.662 & 0.683 & 0.725 & 0.627 & 0.677 & 0.744 \\
\hline 80 & 0.452 & 0.435 & 0.480 & 0.319 & 0.359 & 0.455 & 0.518 & 0.558 & 0.609 & 0.468 & 0.539 & 0.626 \\
\hline \multirow[t]{3}{*}{85} & 0.313 & 0.301 & 0.344 & 0.179 & 0.208 & 0.299 & 0.377 & 0.409 & 0.448 & 0.264 & 0.366 & 0.456 \\
\hline & \multicolumn{12}{|c|}{ Non-Hispanic Black Male } \\
\hline & \multicolumn{3}{|c|}{ Less than High School } & \multicolumn{3}{|c|}{ High School Graduate } & \multicolumn{3}{|c|}{ Some College } & Col & ge Grac & uate \\
\hline Age & 1990 & 2000 & 2010 & 1990 & 2000 & 2010 & 1990 & 2000 & 2010 & 1990 & 2000 & 2010 \\
\hline 25 & 1.00 & 1.00 & 1.00 & 1.00 & 1.00 & 1.00 & 1.00 & 1.00 & 1.00 & 1.00 & 1.00 & 1.00 \\
\hline 30 & 0.966 & 0.976 & 0.979 & 0.977 & 0.982 & 0.985 & 0.992 & 0.993 & 0.993 & 0.992 & 0.994 & 0.996 \\
\hline 35 & 0.929 & 0.951 & 0.955 & 0.949 & 0.964 & 0.968 & 0.980 & 0.985 & 0.986 & 0.980 & 0.987 & 0.992 \\
\hline 40 & 0.883 & 0.921 & 0.928 & 0.913 & 0.942 & 0.950 & 0.964 & 0.975 & 0.977 & 0.963 & 0.978 & 0.986 \\
\hline 45 & 0.833 & 0.880 & 0.898 & 0.869 & 0.908 & 0.928 & 0.947 & 0.961 & 0.966 & 0.945 & 0.964 & 0.978 \\
\hline 50 & 0.776 & 0.817 & 0.851 & 0.816 & 0.856 & 0.894 & 0.924 & 0.939 & 0.950 & 0.917 & 0.941 & 0.966 \\
\hline 55 & 0.712 & 0.742 & 0.790 & 0.747 & 0.783 & 0.838 & 0.891 & 0.905 & 0.922 & 0.880 & 0.905 & 0.944 \\
\hline 60 & 0.632 & 0.656 & 0.705 & 0.645 & 0.695 & 0.753 & 0.836 & 0.860 & 0.877 & 0.824 & 0.860 & 0.905 \\
\hline 65 & 0.536 & 0.562 & 0.613 & 0.521 & 0.587 & 0.648 & 0.756 & 0.805 & 0.815 & 0.740 & 0.786 & 0.847 \\
\hline 70 & 0.431 & 0.462 & 0.504 & 0.376 & 0.450 & 0.536 & 0.660 & 0.716 & 0.734 & 0.601 & 0.682 & 0.774 \\
\hline 75 & 0.318 & 0.342 & 0.397 & 0.236 & 0.310 & 0.407 & 0.510 & 0.591 & 0.643 & 0.433 & 0.553 & 0.669 \\
\hline 80 & 0.203 & 0.228 & 0.284 & 0.117 & 0.162 & 0.258 & 0.350 & 0.441 & 0.515 & 0.276 & 0.396 & 0.506 \\
\hline 85 & 0.105 & 0.118 & 0.170 & 0.026 & 0.054 & 0.125 & 0.187 & 0.274 & 0.348 & 0.120 & 0.225 & 0.341 \\
\hline & & & & & Non & ispantic & ite $F$ & nale & & & & \\
\hline & Less $t$ & an High & School & High & chool G & aduate & & me Coll & & Col & ge Grac & uate \\
\hline Age & 1990 & 2000 & 2010 & 1990 & 2000 & 2010 & 1990 & 2000 & 2010 & 1990 & 2000 & 2010 \\
\hline 25 & 1.00 & 1.00 & 1.00 & 1.00 & 1.00 & 1.00 & 1.00 & 1.00 & .00 & 1.00 & 1.00 & 1.00 \\
\hline 30 & 0.993 & 0.992 & 0.991 & 0.996 & 0.996 & 0.994 & 0.998 & 0.998 & 0.998 & 0.999 & 0.999 & 0.999 \\
\hline 35 & 0.986 & 0.982 & 0.978 & 0.992 & 0.991 & 0.986 & 0.996 & 0.996 & 0.995 & 0.997 & 0.997 & 0.997 \\
\hline 40 & 0.976 & 0.968 & 0.959 & 0.986 & 0.983 & 0.976 & 0.993 & 0.993 & 0.991 & 0.994 & 0.994 & 0.995 \\
\hline 45 & 0.962 & 0.946 & 0.935 & 0.977 & 0.972 & 0.964 & 0.989 & 0.988 & 0.985 & 0.989 & 0.990 & 0.991 \\
\hline 50 & 0.944 & 0.919 & 0.899 & 0.963 & 0.956 & 0.945 & 0.981 & 0.981 & 0.977 & 0.980 & 0.983 & 0.985 \\
\hline 55 & 0.918 & 0.883 & 0.850 & 0.941 & 0.933 & 0.919 & 0.969 & 0.969 & 0.964 & 0.967 & 0.971 & 0.976 \\
\hline 60 & 0.882 & 0.837 & 0.793 & 0.908 & 0.899 & 0.886 & 0.949 & 0.951 & 0.945 & 44 & 0.953 & 0.961 \\
\hline 65 & 0.831 & 0.777 & 0.727 & 0.857 & 0.848 & 0. & 0.917 & 0.923 & 17 & 0.908 & 0.923 & 0.937 \\
\hline 70 & 0.766 & 0.702 & 0.648 & 0.785 & 0.775 & 0.775 & 0.869 & 0.879 & 0.878 & 0.851 & 0.876 & 0.899 \\
\hline 75 & 0.678 & 0.607 & 0.556 & 0.682 & 0.676 & 0.686 & 0.795 & 0.816 & 0.820 & 0.766 & 0.804 & 0.839 \\
\hline 80 & 0.563 & 0.488 & 0.448 & 0.533 & 0.535 & 0.565 & 0.683 & 0.710 & 0.730 & 0.635 & 0.691 & 0.740 \\
\hline 85 & 0.409 & 0.336 & 0.314 & 0.336 & 0.355 & 0.405 & 0.515 & 0.552 & 0.588 & 0.435 & 0.519 & 0.577 \\
\hline & & & & & No & Hispan & White & Iale & & & & \\
\hline & Less t & an High & School & High & chool G & aduate & & me Coll & & Col & ge Grac & uate \\
\hline Age & 1990 & 2000 & 2010 & 1990 & 2000 & 2010 & 1990 & 2000 & 2010 & 1990 & 2000 & 2010 \\
\hline 25 & 1.00 & 1.00 & 1.00 & 1.00 & 1.00 & 1.00 & 1.00 & 1.00 & 1.00 & 1.00 & 1.00 & 1.00 \\
\hline 30 & 0.982 & 0.985 & 0.982 & 0.989 & 0.990 & 0.988 & 0.996 & 0.997 & 0.995 & 0.997 & 0.998 & 0.998 \\
\hline 35 & 0.964 & 0.966 & 0.961 & 0.977 & 0.980 & 0.975 & 0.991 & 0.992 & 0.990 & 0.992 & 0.995 & 0.995 \\
\hline 40 & 0.941 & 0.943 & 0.937 & 0.961 & 0.966 & 0.960 & 0.984 & 0.987 & 0.983 & 0.986 & 0.991 & 0.991 \\
\hline 45 & 0.916 & 0.909 & 0.906 & 0.940 & 0.946 & 0.942 & 0.974 & 0.979 & 0.975 & 0.977 & 0.985 & 0.986 \\
\hline 50 & 0.884 & 0.864 & 0.858 & 0.914 & 0.914 & 0.913 & 0.961 & 0.966 & 0.962 & 0.963 & 0.974 & 0.978 \\
\hline 55 & 0.839 & 0.809 & 0.789 & 0.875 & 0.871 & 0.871 & 0.941 & 0.945 & 0.943 & 0.943 & 0.957 & 0.965 \\
\hline 60 & 0.776 & 0.741 & 0.704 & 0.815 & 0.815 & 0.808 & 0.907 & 0.916 & 0.912 & 0.907 & 0.930 & 0.943 \\
\hline 65 & 0.694 & 0.655 & 0.614 & 0.725 & 0.738 & 0.730 & 0.855 & 0.874 & 0.866 & 0.852 & 0.886 & 0.909 \\
\hline 70 & 0.591 & 0.559 & 0.511 & 0.608 & 0.634 & 0.636 & 0.781 & 0.808 & 0.806 & 0.766 & 0.817 & 0.857 \\
\hline 75 & 0.464 & 0.432 & 0.402 & 0.461 & 0.499 & 0.523 & 0.676 & 0.715 & 0.723 & 0.639 & 0.713 & 0.777 \\
\hline 80 & 0.320 & 0.299 & 0.287 & 0.285 & 0.332 & 0.385 & 0.525 & 0.573 & 0.603 & 0.460 & 0.550 & 0.650 \\
\hline 85 & 0.176 & 0.161 & 0.167 & 0.117 & 0.165 & 0.226 & 0.339 & 0.401 & 0.436 & 0.245 & 0.351 & 0.457 \\
\hline
\end{tabular}

Source: Authors' tabulations based on National Vital Statistics System multiple cause of death data ("NVSS - Public Use Data File Documentation” 2014) and U.S. Census data (Ruggles et al. 2010). 
Appendix Table 2: Life Table Survival Probabilities, conditional on survival to age 25, by educational quartile rank

\begin{tabular}{|c|c|c|c|c|c|c|}
\hline \multirow[b]{3}{*}{ Age } & \multicolumn{6}{|c|}{ Non-Hispanic White Female } \\
\hline & \multicolumn{3}{|c|}{ Bottom 25\% } & \multicolumn{3}{|c|}{ Top $75 \%$} \\
\hline & 1990 & 2000 & 2010 & 1990 & 2000 & 2010 \\
\hline 25 & 1.000 & 1.000 & 1.000 & 1.000 & 1.000 & 1.000 \\
\hline 30 & 0.996 & 0.996 & 0.995 & 0.998 & 0.998 & 0.998 \\
\hline 35 & 0.991 & 0.991 & 0.988 & 0.997 & 0.996 & 0.996 \\
\hline 40 & 0.984 & 0.984 & 0.979 & 0.993 & 0.993 & 0.992 \\
\hline 45 & 0.974 & 0.974 & 0.967 & 0.989 & 0.987 & 0.987 \\
\hline 50 & 0.959 & 0.960 & 0.950 & 0.981 & 0.979 & 0.978 \\
\hline 55 & 0.933 & 0.955 & 0.927 & 0.963 & 0.950 & 0.965 \\
\hline 60 & 0.895 & 0.947 & 0.896 & 0.935 & 0.895 & 0.945 \\
\hline 65 & 0.844 & 0.893 & 0.854 & 0.890 & 0.854 & 0.915 \\
\hline 70 & 0.778 & 0.822 & 0.784 & 0.824 & 0.791 & 0.875 \\
\hline 75 & 0.680 & 0.751 & 0.664 & 0.730 & 0.699 & 0.797 \\
\hline 80 & 0.552 & 0.638 & 0.531 & 0.598 & 0.566 & 0.678 \\
\hline \multirow[t]{3}{*}{85} & 0.384 & 0.440 & 0.369 & 0.418 & 0.398 & 0.508 \\
\hline & \multicolumn{6}{|c|}{ Non-Hispanic White Male } \\
\hline & \multicolumn{3}{|c|}{ Bottom 25\% } & \multicolumn{3}{|c|}{ Top $75 \%$} \\
\hline Age & 1990 & 2000 & 2010 & 1990 & 2000 & 2010 \\
\hline 25 & 1.000 & 1.000 & 1.000 & 1.000 & 1.000 & 1.000 \\
\hline 30 & 0.988 & 0.991 & 0.989 & 0.996 & 0.997 & 0.996 \\
\hline 35 & 0.975 & 0.981 & 0.977 & 0.991 & 0.993 & 0.991 \\
\hline 40 & 0.957 & 0.968 & 0.964 & 0.985 & 0.987 & 0.986 \\
\hline 45 & 0.935 & 0.948 & 0.946 & 0.975 & 0.979 & 0.978 \\
\hline 50 & 0.907 & 0.920 & 0.919 & 0.962 & 0.966 & 0.965 \\
\hline 55 & 0.860 & 0.909 & 0.879 & 0.933 & 0.925 & 0.946 \\
\hline 60 & 0.797 & 0.894 & 0.823 & 0.885 & 0.854 & 0.916 \\
\hline 65 & 0.713 & 0.833 & 0.753 & 0.810 & 0.791 & 0.872 \\
\hline 70 & 0.608 & 0.739 & 0.651 & 0.705 & 0.702 & 0.815 \\
\hline 75 & 0.466 & 0.598 & 0.509 & 0.567 & 0.579 & 0.710 \\
\hline 80 & 0.310 & 0.441 & 0.356 & 0.392 & 0.415 & 0.564 \\
\hline 85 & 0.160 & 0.220 & 0.208 & 0.209 & 0.244 & 0.368 \\
\hline
\end{tabular}

Source: Authors' tabulations based on National Vital Statistics System multiple cause of death data ("NVSS - Public Use Data File Documentation” 2014) and U.S. Census data (Ruggles et al. 2010). 